
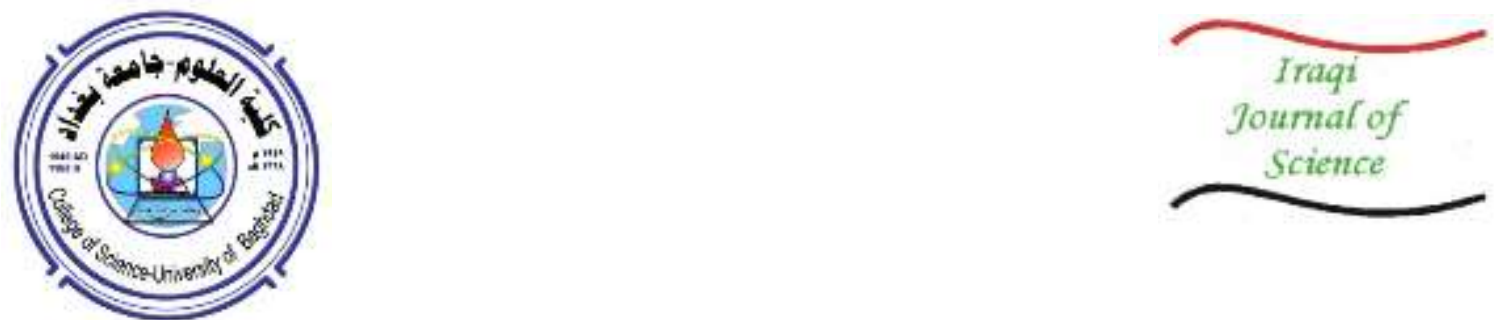

\title{
A Comparative Study between Conventional Pap Smear and Liquid-Based Cytology: A Clinco-Cytological Study of Iraqi Women with Some Health Problems of Cervix
}

\author{
Huda Hameed K. Alabbody ${ }^{*}$, Zahraa Adnan G. Al-Ghuraibawi \\ National Cancer Research Center, Baghdad University
}

Received: $26 / 4 / 2019 \quad$ Accepted: 17/7/2019

\begin{abstract}
A cervical screening by Pap test is necessary in recognizing precancerous and cancerous cases to reduce mortality due to cervical cancer among women. Regular screening and follow up can make it easier to early diagnose and eventually, to treat and control cervical cancer.

This study aimed to detect atypical pathological changes of the vagina and uterine cervix of a sample of Iraqi women by macro- and micro-examination, and to determine the link with the demographic features. Also the study aimed to evaluate the two Pap smear techniques; the conventional and the base liquid methods.

The study included 50 women with genital health problems (18-50 years old) who were referred to the National Cancer Research Center (NCRC), the University of Baghdad, during the period from $1^{\text {st }}$ April to $30^{\text {st }}$ of September 2018. Both visual inspection of the uterine cervix and Papanicolaou smear were performed for all of the participants.

The results showed that most patient women (96\%) were married and sexually active, with $51 \%$ being married under 20 years of age .Visual inspection of the cervix showed that $30 \%$ of the women had translucent, opaque or erosion lesions. Upon cytology examination, $92 \%$ of the women showed nonspecific inflammation, $70 \%$ revealed reactive squamous metaplasia, $10 \%$ had Koilocytotic atypia, and $8 \%$ suffered from cervical intraepithelial neoplasia (CIN1) or low grade squamous intraepithelial lesion (LGSIL). Contraception was used by $82 \%$ of the patients, while $36 \%$ used pills. The causes of the referral to the centre were abnormal vaginal discharge (44\%) and post-coital bleeding "andlor" dyspareunia (20\% each). Lastly, $74 \%$ of the participants did not make this test previously. Liquid-based cytology technique outperformed conventional pap smears because of improved fixation, decreased impurities factors, and standardization of cell transfer.

We conclude that routine screening and Pap smear testing for uterine cervix and vagina might be useful to prevent the occurrence of precancerous lesions in the genital system of sexually active women. We recommend to apply this test before and after treatment and to activate the cellular examination in the basal fluid method
\end{abstract}

Keywords: Pap, smear, precancerous, cancer, cervix, women, Iraq 


\section{دراسة مقارنة بين مسحة عنق الرحم التقليدية و طريقة السوائل القاعدية : دراسة خلوية سريرية للنسوة العراقيات المصابات بخلل صحي في عنق الرحم \\ هدى حميد كاظم العبودي"، زهراء عدنان غضبان الغريباوي \\ المركز الوطني الريادي لبحوث السرطان ,جامعة بغداد}

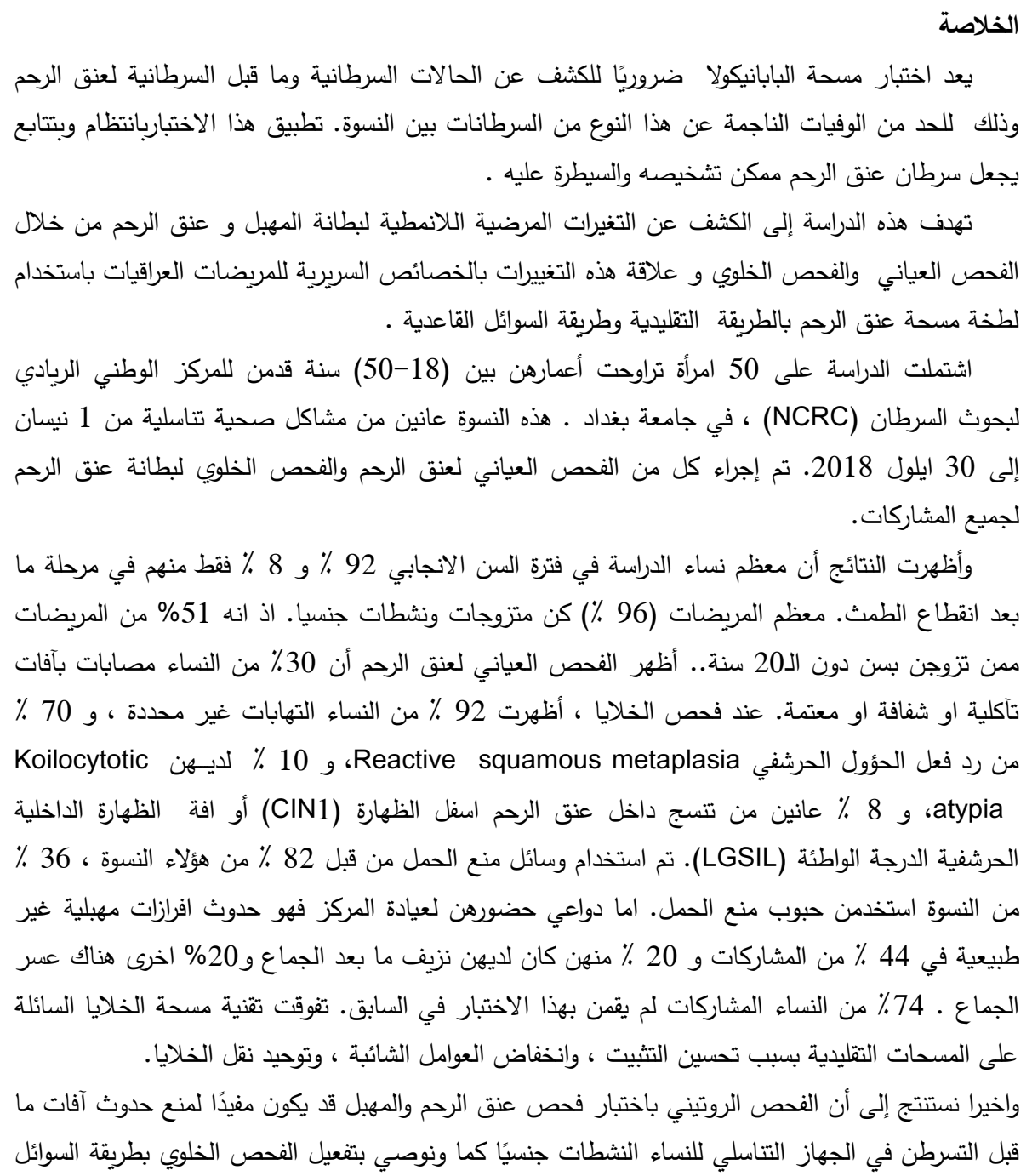

القاعدية.

\section{Introduction}

Cervical cancer is the third most common cancer among women and a major cause of morbidity and mortality worldwide [1]. Data indicates that a large quantity of cervical cancer can be prevented through organized cervical screening. Almost all cervical cancers are caused by human papilloma virus (HPV), with HPV types 16 and 18 collectively account for $70 \%$ of cervical cancers worldwide [2]. Numerous Western countries introduced HPV vaccination programs. However, low- and middleincome countries lack a compulsory screen program. As a result, cervical cancer patients are often diagnosed in the advanced stages in these countries [1]. The incidence rate of cervical cancer is low in Iraq, like many other Islamic countries as of religious and social commitments. [3].

Definitely, efforts must be improved to suitably identify and manage cervical neoplasia. Chronic inflammation, either specific or non-specific, was shown to be associated with malignancy and was thought to be one of the dependable aspects for carcinogenesis. Persistent inflammation leads to increased cellular turnover, particularly in the epithelium, and offers a pressure that result in bringing the cells to a high risk of malignant transformation [2]. Inflammatory Pap smear is the most common 
report that the gynecologists receive even when the cervix appears normal [4]. Papanicolau classifications of inflammatory smears advise to repeat the smear after treating the infection [5]. However, this does not specify the type of infection, and the present reporting of Pap smear by the Bethesda system reports on specific infections and classifies them under benign cellular changes [6]. The cervical screening for benign cellular changes recommends treatment of infection if indicated and performing a repeat Pap smear in 4 to 6 months time and, if the inflammatory changes persist, the patient should be subjected to colposcopy [7]. In practice, however, this is not always followed, especially in the developing countries, including Iraq. The significance of cervical cytology with atypia was extensively studied [8]. There is a great controversy regarding the optimal management of women with persistent inflammatory changes without atypia; some considering it less likely to be associated with dysplasia and others recommend further estimate as it is linked with a high incidence of cervical intraepithelial neoplasia (CIN) $[9,10]$. Hence, we undertook this study to detect precancerous and cancerous changes by macro and micro examination of the vagina and the uterine cervix, by using Pap smear staining in conventional and base liquid techniques and to determine the link with the demographic features..

\section{Materials and methods \\ Samples}

Fifty women aged 18-50 years (mean $35.18 \pm 9.70$ ) referred to the National Cancer Research Center (NCRC), University of Baghdad, during the period from $1^{\text {st }}$ April to $30^{\text {st }}$ September 2018. These participants suffered from genital health problems and did not undergo hysterectomy. In this study all patients were aware about Pap smear and its purpose. Demographic variables and databases taken from each participant included age, marital and menopausal statuses, parity, history of contraception, history of sexually transmitted diseases, and hormone replacement therapy.

\section{Cervix inspection and Pap smear}

The visual inspection to the cervix and vagina along with the Pap smear test were performed at the NCRC oncologic clinic. The smears were collected from the participants using a broom brush with appropriate instructions to the women [11]. The pointed tip of the brush was introduced through the external and the squamo-columnar junction was scraped by rotating the brush to 360 . The smear was transferred directly and evenly spread onto a microscope slide and immediately fixed in $95 \%$ ethanol. This method is known as conventional Pap smear method [12].

Manual liquid based cytology (MLBC) was applied in 10 samples collected as the same way of the conventional. The head of the cervix brush was detached and deposited into a small bottle of preservative liquid (The Thin Prep Pap test). In the laboratory, the liquid was treated to remove other elements such as mucus before a layer of cells was placed on a slide. Specimens were collected in vials then were shaken vigorously, poured into a centrifuge tube containing $4 \mathrm{ml}$ cleaning solution, and centrifuged at $3000 \mathrm{rpm}$ for 10 minutes. To the residual pellet, $500 \mu 1$ of cellular base was added and vortex mixed. $50 \mu \mathrm{l}$ of each sample was pipetted onto a slide, smeared, dried and stained [13].

The slides from the two methods were stained for cytological diagnosis according to the method of Papanicolaou stain. The Pap staining procedure was performed according to the procedure described by Ali and Al Qzweni [12]

All the slides were examined under the light microscope using 40X magnification. Then Cervical Pap smears were examined by a pathologist in the Department of Pathology in the NCRC. According to the 2001 Bethesda classification, the smears were characterized as in the method of Solomon et al [14].

Statistical analysis: The two statistical programs SPSS V.22 and Microsoft Office Excel 2003 for Windows were used to analyze the data that was presented as frequency, percentage, and mean $\mp$ standard deviations (SD) of the variables.

\section{Results}

Demographic characteristics: Most women in this study were in their menstrual and reproduction period $(92 \%)$ whereas $8 \%$ were postmenopausal. Approximately $86 \%$ of the participants were housewives, followed by $12 \%$ employed, while the lowest proportion $(2 \%)$ were students. The married women constituted $96 \%$, whereas both divorced and widows were $2 \%$ each. $67 \%$ of the participants used different types of contraceptives, while pills have been the most frequently used (36\%). In contrast, $33 \%$ women did not use contraceptives. $70 \%$ of the participants had regular menstrual cycle. Finally, women's answers varied concerning their reasons for visiting NCRC; $44 \%$ had abnormal 
vaginal discharge, while $20 \%$ was the proportion for both participants complaining from post-coital bleeding or dyspareunia (Figure-1). The youngest in postmenopausal age was 45 years old and the oldest was 50 years old. Ages at marriage ranged between 13 to 32 years old (with a mean of $19.70 \pm$ 4.30). Women's ages at the first birth were 15 to 33 years old with a mean of $21.27 \pm 4.08$ years (Table-1, Figures-1, 2)

Table 1-The reproductive status and the age of the patients

\begin{tabular}{|c|c|c|c|c|c|}
\hline Reproductive status and Age & Total no. & Minimum & Maximum & Mean & Std. Deviation \\
\hline Current age & 50 & 18 & 50 & 35.18 & 9.70 \\
\hline Age at marriage & 50 & 13 & 32 & 19.70 & 4.30 \\
\hline Age at 1 $\mathbf{s}^{\text {st }}$ pregnancy & 45 & 14 & 32 & 20.40 & 4.11 \\
\hline Age at $\mathbf{1}^{\text {st }}$ child birth & 45 & 15 & 33 & 21.27 & 4.08 \\
\hline Age at menopause & $4(8 \%)$ & 36 & 53 & 48 & 2.94 \\
\hline Age at menstruation & 50 & 9 & 15 & 11 (mode) & - \\
\hline
\end{tabular}

Visual inspection: The uterine cervix showed normal appearance in $50 \%$ of the investigated, while a proportion of $30 \%$ was recorded for each of the participants with translucent, opaque or erosion lesions. The lesions were whitish to yellow, and ranged from a few millimeters to $2 \mathrm{~cm}$ in diameter. The genital warts of cervix were atypical in $4 \%$ of the participants (Table-1).

Microscopic inspection: Based on the cytology description of the Bethesda Terminology, the smears showed some cytopathological changes such as heavy acute inflammatory cells (Non specific cervicitis) in $92 \%$ of the participants, infiltrates with clusters of mild to moderate dysplastic epithelial cells or reactive squamous metaplasia in $70 \%$, CIN1 or LGSIL (cervical intraepithelial neoplasia or low grade squamous intraepithelial lesion) in $8 \%$, clusters and sheets of benign-abnormal exfoliated endometrial cells in 14\%, atypical squamous cells of undetermined significance (ASCUS) in 10\%, and numerous sheets of endocervical glandular dysplasia in 5\%. Some cases had specific inflammations such as being positive for candida albicans which appeared like pseudohyphi, blastospores and chlamydospores, or Trichomons vaginalis which were observed as free or attached to the cytoplasm of the cells, as well as microflora infections. All of these cases formed $8 \%$ of the samples. Some cases $(10 \%)$ showed the presence of koilocytotic atypia. One case $(2 \%)$ showed uncommon epithelium (A tadpole cells) with narrow elongated opposite end and an eccentric, rounded, hyperchromatic nucleus or nuclei within often keratinised cytoplasm. ... (Table-2) 


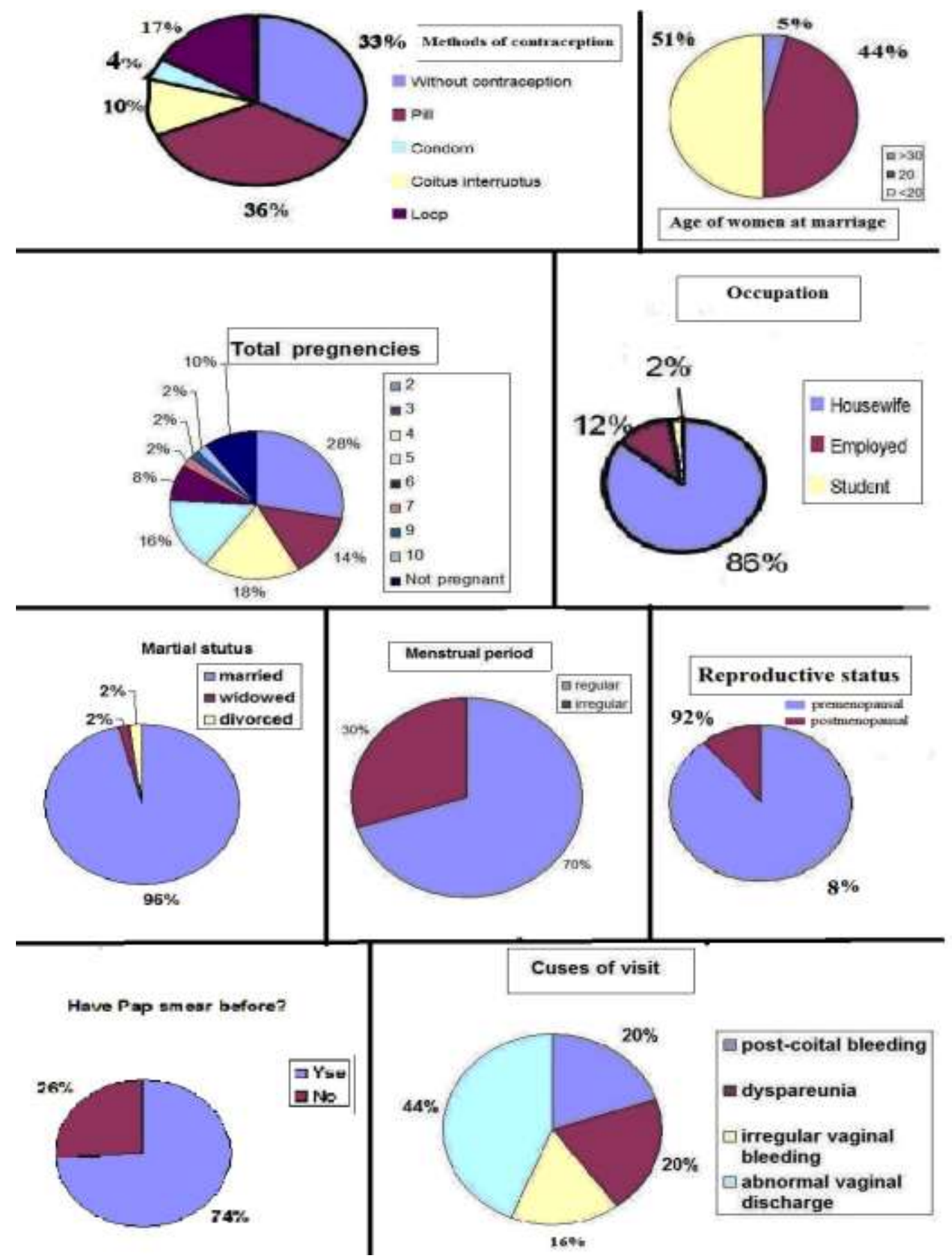

Figure 1-Demographic characteristic of the patients

Table 2-Visual inspection and cytological changes of the cervix of the patients

\begin{tabular}{|c|c|c|}
\hline Clinical and cytological findings of the uterine cervix & No. & $\%$ \\
\hline Visual inspection & 25 & 50 \\
\hline Normally looking & 2 & 4 \\
\hline Genital warts & 15 & 30 \\
\hline Erosion, translucent, opaque lesions & & \\
\hline Cytological inspection
\end{tabular}




\begin{tabular}{|c|c|c|}
\hline Reactive squamous metaplasia & 35 & 70 \\
\hline Koilocytotic atypia (Possibility of Human Papilloma Virus infection) & 5 & 10 \\
\hline $\begin{array}{c}\text { CIN1 or LGSIL (Cervical Intraepithelial Neoplasia or Low grade } \\
\text { squamous intraepithelial lesion) }\end{array}$ & 4 & 8 \\
\hline Clusters and sheets of benign-abnormal exfoliated endometrial cells & 7 & 14 \\
\hline Atypical squamous cells of undetermined significance (ASCUS) & 5 & 10 \\
\hline Endocervical glandular dysplasia & 5 & 10 \\
\hline Inflammation & & 96 \\
\hline Non specific inflammation (endocervicitis, cervicitis, vaginitis) & 46 & 92 \\
\hline Specific inflammation by Candida albicans or Trichomons vaginalis & 4 & 8 \\
\hline
\end{tabular}

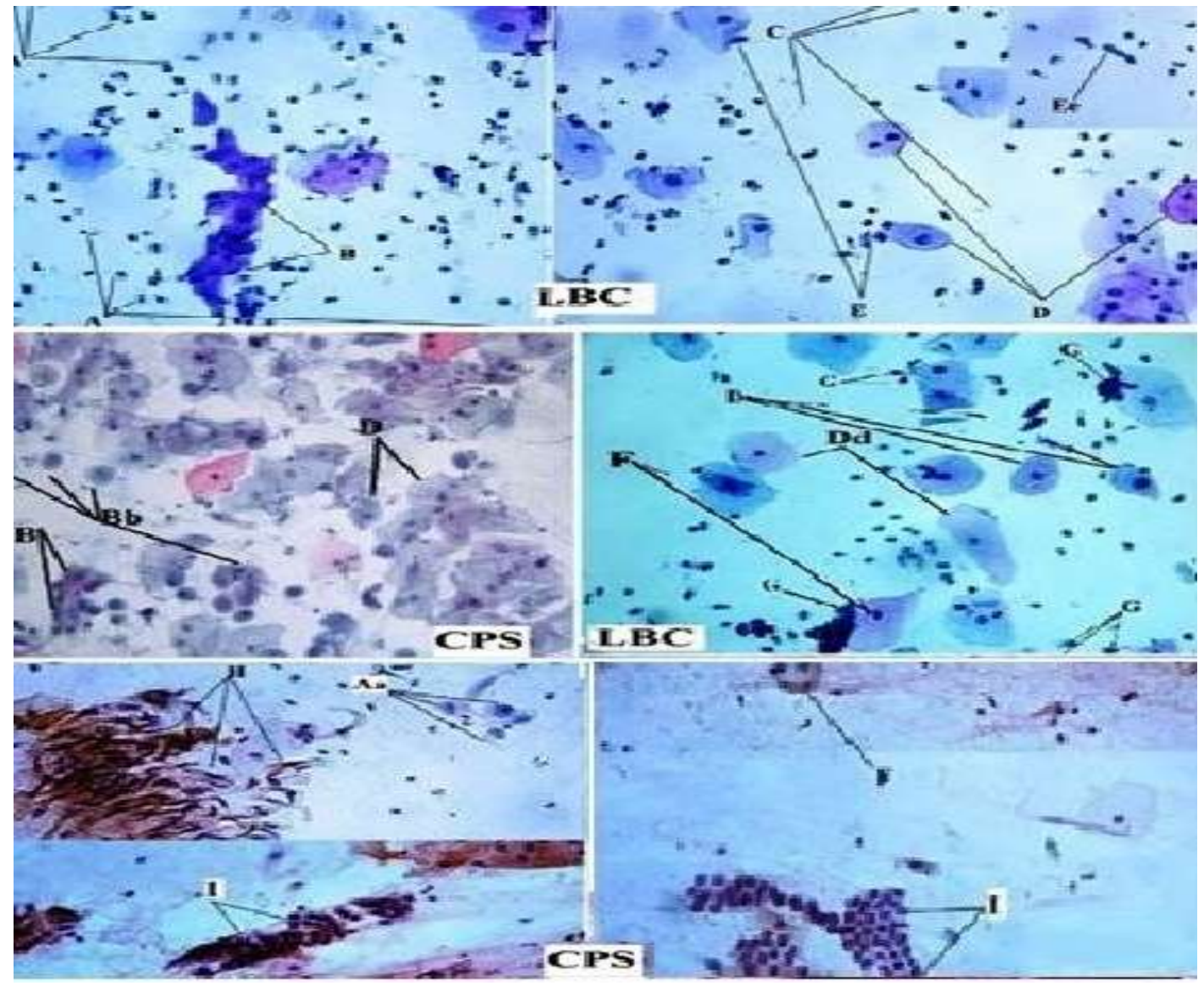

Figure 2- Multiple fields of Pap smear of women stained with LBC (liquid based cytology) or CPS (conventional Pap smear). Smears shows some inflammatory cells (Non specific cervicitis) (A), CIN1or LGSIL (cervical intraepithelial neoplasia) or (low grade squamous intraepithelial lesion) (Aa), Clusters and sheets of benign-abnormal exfoliated endometrial cells (B), numerous sheets of atypical endocervical cells and endocervical glandular dysplasia(Bb), microflora : lactobaceli infection (C), Atypical squamous cells of undetermined significance ASCUS (D), reactive squamous intraepithelial metaplasia (Dd), Trichomons vaginalis (E) which were observed as free or attached to the cell's cytoplasm, candida albicans which appeared like blastospores (Ee), koilocytotic atypia (F), degenerated blood and necrotic debris $(\mathrm{G})$, and a tadpole cells $(\mathrm{H})$ which were observed as a narrow elongated opposite end and an eccentric cells. $400 \mathrm{X}$. 


\section{Discussion}

This study was performed to determine the potential impact of some factors on cervix health of Iraqi women. Our findings show that most women (96\%) were married while only $4 \%$ were unmarried. Among married participants, $51 \%$ were under 20 years of age. These results imply that sexual activity has a major role in the exposure of female reproductive system to many health problems. It was reported that most sexually active women will be infected with HPV at some point throughout their lives $(7,8)$.

On the other hand, postmenopausal women showed low risk of developing healthy problem of cervix [15]. This is consistent with our data, when only $10 \%$ of the women enrolled in this study were in postmenopausal period.

Moreover, in this study, the number of births or abortions, regularity of menstrual cycle, residence and occupation did not have a significant value on the health of women. Regarding contraception, about two-thirds (68\%) of all participants used different types of contraceptives, and the most commonly used were pills (36\%). It was reported by a previous study that pills were the major risk factors for cervical cancer. Administration of oral contraceptives for more than five years has been estimated to double the risk, whereas more than ten-year uptake has quadruple risk [16]. Previous studies found that there might be a significant correlation between abnormal Pap smears with hormonal contraception, post coital bleeding and vaginal discharge that make women seeking for a clinic to check up cervix status. In this paper, the percentage of women who suffered from abnormal vaginal discharge was $34 \%$, with $20 \%$ post coital bleeding. Abnormalities including vaginal secretions, abdominal pain and itching are the most important signs of cervical inflammation [17].

In this research, liquid-based technique was applied. Its proponents argue that liquid-based preparations outperform conventional smears because of improved fixation, decreased obscuring factors, and standardization of cell transfer. Proponents point out that, in direct smears, the cells are not transferred in a representative fashion and that up to $90 \%$ of the material scraped from the cervix may be discarded with the sampling device. Liquid-based cytology is a new method of preparing cervical samples for cytological examination. Unlike the conventional 'smear' preparation, it involves making a suspension of cells from the sample and this is used to produce a thin layer of cells on a slide. The technique allows more accurate results [18]. There are very few studies in the literature where the incidence of premalignant and malignant lesions was linked to cases of inflammatory Pap smear. Inflammation can obscure the presence of few malignant cells and may result in high false negative rates, which may be reduced by employing liquid based cytology [19]. However, it was reported that liquid based cytology was not cost-effective to be applied in the developing countries [20].

In this research, there were mild and moderate cervix problems, such as erosion in $30 \%$ of participants and warts in $4 \%$. If at least the cervical lesion shows benign cellular changes like reactive squamous metaplasia or abnormal exfoliated endometrial cells, it is necessary to adhere to the treatment of the problem and to repeat the Pap smear in a period of 4-6 months. If inflammatory changes persist, the patient should be subjected to vaginal endoscopy (7).

The microscopic examination revealed non-specific vaginitis, cervicitis and endocervicitis in $92 \%$ of the women, extending to the endocervix with reactive squamous metaplasia in $70 \%$ and cervical intraepithelial neoplasia (CIN1) or low grade squamous intraepithelial lesion (LGSIL) in 8\%, which can be termed as precancerous lesions. These cases could be treated with low cost and short time to avoid progression to cervical cancer after a long period [6]. It is known that cervical cancer is preceded by a long stage of pre-invasive disease called cervical intraepithelial neoplasia (CIN), which is classified into grades I, II, and III. If these lesions are left without treatment, particularly the highgrade, CIN II and III, they largely might progress into cancer. Using the Papanicolaou's technique for the cervico-vaginal smear, these alterations can be detected [21].

Moreover, in the present study, mild koliocytotic atypia of cervical squamous cells was demonstrated in $10 \%$ of the participated women. Thus, the possibility of HPV infection cannot be excluded. Approximately $99.7 \%$ of cervical cancer cases occur due to infection with HPV [6,7]. The infection with this virus can recover without any therapeutic intervention in most women, however, those with persisting HPV infection are at risk for CIN II, III and cervical cancer [22,]. In the developing countries, there is a tendency for increasing the incidence of the disease that is attributed to the early beginning of sexual activities, certain sexual behaviors like a high number of multiple 
partners, and infrequent use of condoms, as well as multiple pregnancies, immunosuppression and infectious agents, mainly HPV [23]. In addition, other contributing factors can be the use of oral contraceptives, occupational factors, and dietary habits [24].

Reports state that young women possess large areas of immature metaplastic cervical epithelium, which seems to be more susceptible to infection by carcinogenic HPV than other squamous epithelia. If sexual activity begins at an early age, especially with multiple partners harboring carcinogenic HPV, then the women will face high risk for cervical cancer development. Cervix carcinoma induced by HPV can progress within couple of years post-infection of unstable squamous epithelia of endocervix. However, most cancers arise from benign changes to precancerous lesions that proceed from one stage to another throughout 10-30 years. Over time, uninfected metaplastic squamous epithelia become mature and appear more susceptible to viruses of no-risk or low-risk, e.g. HPV-6 [25].

Likewise, our findings showed that $8 \%$ of the women had severe degree of cervicitis/endocervicitis due to infection with Candida albicans and Trichomons vaginalis, which were observed via the Pap smear test. This technique demonstrated its ability to diagnose some microbiological agents such as Actinomyces spp., Herpes Simplex virus or HPV along with C. albicans and T. Vaginalis [26].

Thus, in the absence of a well-organized screening program, a reliable and cheap approach such as the Pap smear test is required for at least a preliminary diagnosis of uterine cervix problems. This has to be consistent with increasing women's awareness for attending clinics and hospitals for a routine checkup against gynecologic diseases including cervical carcinoma [27-28].

\section{Conclusion}

Pap smear is one of the most important methods for the early detection of cervical cancer, which requires follow-up to detect genital problems, especially pre-cancerous and cancerous lesions. If lesions and infections could be diagnosed and treated, then the prevention occurs and later the development of a serious pathology problem might be stopped. We strongly recommend the sexually active women to undergo routine cervical smear screening because they are more prone to contact infections than others.

\section{References}

1. Arbyn, M., Castellsague, X., de Sanjose, S., Bruni, L., Saraiya, M. and Bray, F. 2011. Worldwide burden of cervical cancer in 2008. Ann Oncol, 22(12): 2675-86.

2. Tracy, L., Gaff, H.D., Burgess, C., Sow, S., Gravitt, P.E. and Tracy, J.K. 2011 Estimating the impact of human papillomavirus (HPV) vaccination on HPV prevalence and cervical cancer incidence in Mali. Clin Infect Dis Mar, 52(5): 641-45.

3. Al Hilfi, Th. K., Lafta, R. and Burnham G. 2013. Health services in Iraq. Review, 381 (4) 939-948

4. Vassilakos, P. 1994. Management of Suboptimal Cytologic smears: Persistent inflammatory smears. Acta Cytogica, 38(4): 531-536.

5. 5 .Rimel, B. J., Ferda, A., Erwin, J, Dewdney S. B., Seamon, L.; Gao, F, Desimone, C, Cotney, K. K, Huh, W and Massad, L. S. 2011. Cervicovaginal Cytology in the Detection of Recurrence After Cervical Cancer Treatment. Obstetrics \& Gynecology, 118(3): 548-553.

6. Moss, S.F., Blaser M.J. 2005 Mechanisms of Disease: Inflammation and origins of cancer. Nat Clin Pract Oncol, 2(2): 90-97.

7. Engelstad LP, Stewart SL, Nguyen BH, Bedeian KL, Rubin MM, Pasick R.J., et al. 2001 Abnormal Pap smear follow-up in a high-risk population. Cancer Epidemiology Biomarkers \& Prevention, 10(10): 1015-1020.

8. Alabbody, H. H. 2018. Demographic and Clinical Study on Patients Referred to The National Cancer Research Center for Pap Smears. Iraqi Journal of Science, 59 (4C): 2159-2167.

9. Kiviat, N.B., Paavonen J.A., Brockway, J., Critchlow, C.W., Brunham, R.C. and Stevens, C.E. 1985 Cytologic manifestations of cervical and vaginal infections. Epithelial and Inflammatory changes. Journal of the American Medical Association JAMA, 253(7): 989-996.

10. Atikson, K.M. 1997. Benign Cellular Changes. In: Bonfigilo T, Erogen YS Editors. Gynaecologic Cytopathology. Philadelphia: Lppincot Raven Publishers, 33 - 42.

11. Mehta, V., Vasanth, V. amd Balachandran, C. 2009. Pap smear. Indian J Dermatol Venereol Leprol., 75: 214-216. 
12. Ali, M.A. and Al Qzweni, A. 2013. Cervical Pap smear is gold diagnostic tool for cervical cancer. Kufa Med J., 16(2): 16-23.

13. Davey, E., Assuncao, J. and Irwig, L. 2007. Accuracy of reading liquid based cytology slides using the ThinPrep Imager compared with conventional cytology: prospective study. British Medical Journal, 335(7609): 31.

14. Solomon, D., Davey, D., Kurman, R., Moriarty, A., Connor, D., Prey, M., Raab, S., Sherman, M., Wilbur, D., Wright, T. and Young, N., Forum Group M, Bethesda W. 2002. The 2001 Bethesda System: terminology for reporting results of cervical cytology. Journal of the American Medical Association JAMA. 287: 2114-2119.

15. Speck, N.M., Pinheiro, J. S., Pereira, E, R., Rodrigues, D., Focchi, G.R. and Ribalta, J.C. 2015. Cervical cancer screening in young and elderly women of the Xingu Indigenous Park: evaluation of the recommended screening age group in Brazil. Einstein Sao Paulo, 13: 52-57.

16. Gorenoi, V., Schonermark, M.P. and Hagen, A. 2007. Benefits and risks of hormonal contraception for women. GMS Health Technology Assessment, 3: 1-10.

17. McLachalan, N., Patwardhan, J.R. Ayer, B. and Pacey, N.F. 1994. Management of suboptimal cytologic smears: Persistent inflammatory smears. Acta Cytologica, 38(4): 531-536.

18. Kirschner, B., Simonsen, K. and Junge, J. 2006. Comparison of conventional Papanicolaou smear and SurePath liquid-based cytology in the Copenhagen population screening prgramme for cervical cancer. Cytopathology. ; 17: 187- 194.

19. Marchand, L, Van Dinter, M., Mundt, M., Dingel. W., Klein, G. 2003 Current cervical cancer screening practices of Dane Country, Wsconsin Primary care clinicians. WMJ; 102: 3540.

20. Virginia, A. Moyer, M.D., on behalf of the U.S. Preventive Services Task Force2012. Screening for Cervical Cancer: U.S. Clinical Guideline Annals of Internal Medicine; 156(12): 880-893.

21. McCredie, M.R., Sharples, K.J., Paul, C., Baranyai , J., Medley, G., Jones, R.W. and Skegg, D.C. 2008. Natural history of cervical neoplasia and risk of invasive cancer in women with cervical intraepithelial neoplasia 3: a retrospective cohort study. Lancet Oncol., 9(5): 425-434.

22. Dillner, J., Meijer, C.J., Von Krogh, G. and Horenblas, S. 2000. Epidemiology of human papillomavirus infection. Scand J Urol Nephrol Suppl., 34(205): 194-200.

23. Muhammad O.Z. 2016. The Cervical screening in Erbil does not target every woman. Polytechnic ; 6(3): 474-490.

24. Barzanjy, B. K., Talat, L. M., and Sherzad, A. I. 2013. "Cervical dysplasia: assessment and risk factors among women attending the Maternity Teaching Hospital in Erbil, Kurdistan-Iraq." Zanco J. Med. Sci. 17(1): 286-293.

25. Basu S.J., and Jenson, A. 2002. Cervical Cancer: Etiology, Pathogenesis, Treatment, and Future Vaccines. Asian Pac J Cancer Prev., 3: 207-214.

26. WHO. 2013. Laboratory diagnosis of sexually transmitted infections, including human immunodeficiency virus. WHO Press, World Health Organization, Switzerland. 2013.

27. Al-Alwan, N.A. and Attof, W. 2016 Assessing the knowledge, attitude and practices towards cervical cancer screening among a sample of Iraqi female population. International The $3^{\text {rd }}$ Scientific Conference of Medical and Health Specialties: 23-24.

28. Attof, W., Alwandawi, N. and Algomele, H. 2014. Knowledge, attitude and practice of workers about the cervical cancer and Pap smear in the College of Nursing. Kufa J. Nursing Sciences. 4(3): $1-7$. 